\title{
POSTPRANDIAL LIPOPROTEIN METABOLISM
}

\section{SUNIL SETHI, M. J. GIBNEY* AND CHRISTINE M. WILLIAMS $\dagger$}

Nutritional Metabolism Research Group, School of Biological Sciences, University of Surrey, Guildford GU2 5XH and * Division of Nutritional Sciences, Department of Clinical Medicine, Trinity College Medical School, St James Hospital, Dublin 8, Ireland

\section{CONTENTS}

INTRODUCTION .

DIGESTION AND ABSORPTION OF FAT AND CHYLOMICRON PRODUCTION

DIGESTION AND ABSORPTION OF DIETARY LIPID . . . . . . . 162

CHYLOMICRON FORMATION . . . . . . . . . . . . . . . . . 163

POSTPRANDIAL CHYLOMICRON METABOLISM . . . . . . . 164

CHYLOMICRON HYDROLYSIS AND LIPOPROTEIN LIPASE . . . . 164

CHYLOMICRON REMNANT CLEARANCE . . . . . . . . . . . 165

REVERSE CHOLESTEROL TRANSPORT, CHOLESTEROL ESTER TRANSFER

PROTEIN AND TRIACYLGLYCEROL-RICH LIPOPROTEINS . . . . 166

FACTORS INFLUENCING POSTPRANDIAL LIPAEMIA . . . . . 168

DIETARY INFLUENCES ON POSTPRANDIAL LIPAEMIA . . . . . . 169

Effect of meal composition . . . . . . . . . . . . . . . . . . .

Effect of dietary fatty acid composition . . . . . . . . . . . . . $\quad . \quad 170$

PHYSIOLOGICAL FACTORS INFLUENCING POSTPRANDIAL LIPOPROTEINS · 171

THE NATURE OF THE POSTPRANDIAL RESPONSE TO THE INGESTION OF

LIPID . . . . . . . . . . . . . . . . . 172

POSTPRANDIAL LIPAEMIA, ATHEROGENIC LIPOPROTEINS AND CORONARY ARTERY DISEASE . . . . . . . . . . . 173

MECHANISMS BY WHICH POSTPRANDIAL LIPAEMIA PREDISPOSES TO

CORONARY ARTERY DISEASE . . . . . . . . . . . . 175

ATHEROGENICITY OF CHYLOMICRON REMNANTS . . . . . . . 176

POSTPRANDIAL LIPAEMIA AND CORONARY ARTERY DISEASE . . . 177

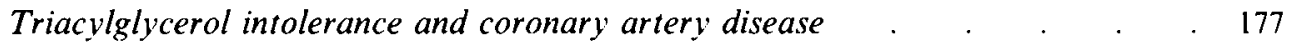

Triacylglycerol intolerance: effects on other circulating lipoproteins . . . $\quad 178$

CONCLUSIONS . . . . . . . . . . . . . . . . 179

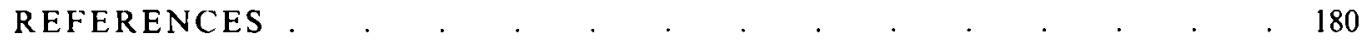

\section{INTRODUCTION}

Almost all the epidemiological investigations of plasma lipids as risk factors for ischaemic heart disease have relied on fasting values, largely to avoid the confounding effects of recent meal ingestion on plasma lipids, particularly triacylglycerol levels. In reality, most human

† Send all correspondence to Dr Christine M. Williams at the above address. 
populations eat 4-6 times per day and therefore spend most of their day in the postprandial state. The normal plasma lipid transport system is subjected to a physiological challenge at each intake of a fatty meal, and the magnitude of the ensuing postprandial lipaemia varies greatly among individuals reflecting varying capacities to metabolize dietary fat. With the input of newly synthesized chylomicrons which constitute postprandial lipaemia, there are also significant associated perturbations in other plasma lipoproteins. Recent evidence suggests that postprandial lipaemia may be an important factor in atherosclerosis either directly through the atherogenic properties of postprandial triacylglycerol-rich lipoproteins and their remnants, and/or indirectly by influencing compositional changes in other lipoproteins implicated in the process of atherosclerosis.

In recent years the potential importance of postprandial lipoproteins in the pathogenesis of atherosclerosis has received greater recognition and a review of the current literature seems appropriate.

\section{DIGESTION AND ABSORPTION OF FAT AND CHYLOMICRON PRODUCTION}

A brief outline of the major steps in the digestion and absorption of dietary lipids and subsequent formation of chylomicrons is provided here but a more detailed review is given by Carey et al. (1983).

\section{DIGESTION AND ABSORPTION OF DIETARY LIPID}

The usual dietary intake of fat ranges from 50 to $100 \mathrm{~g}$ daily. Most of it is in the form of triacylglycerols, with cholesteryl esters and phospholipids constituting only a small fraction. Ingested triacylglycerols contain saturated fatty acids such as palmitic and stearic acids, and unsaturated fatty acids such as oleic and linoleic acids. Absorption of dietary triacylglycerols is more than $95 \%$ while that of cholesterol is about $40 \%$.

The pancreatic enzymes involved in lipid digestion include pancreatic lipase (EC 3.1.1.3), cholesterol esterase (EC 3.1.1.13), and phospholipase (EC 3.1.4.4). The hydrolysis of triacylglycerols occurs sequentially, one of the end fatty acids being removed at a time, yielding in turn $s n-1$ and $s n-3$ diacylglycerols and then an $s n-2$ monoacylglycerol. Less than $5 \%$ of the fat ingested remains in the form of di- and triacylglycerols. Hydrolysis of $s n-2$ monoacylglycerols occurs only after isomerization of the fatty acid to the $s n-1$ position, but this is unusual, so that most $s n-2$ located fatty acids are absorbed in their monoacylglycerol form. Polyunsaturated fatty acids (PUFA) are usually located at the $s n$ 2 position (Johnston, 1968).

Part of the dietary cholesterol is in the form of cholesteryl esters which are hydrolysed in the intestinal lumen by the pancreatic cholesterol esterase to form cholesterol and fatty acids. Phospholipids are hydrolysed by phospholipases. Fatty acids, glycerol, monoacylglycerols, some di-, and triacylglycerols, cholesterol and lysophospholipids, the end products of lipid hydrolysis, are then made available for absorption through micellar solubilization brought about by bile acids.

Within the enterocyte, the subsequent fate of the fatty acids depends on their length. Fatty acids containing less than 10-12 carbon atoms (small and medium chain fatty acids) pass from the mucosal cells directly without reesterification and, bound to albumin, they are transported as non-esterified fatty acids to the liver and other tissues. Readily soluble free glycerol from lipid hydrolysis is also transported by portal blood. Fatty acids with more than 12 carbon atoms and the absorbed cholesterol are re-esterified to triacylglycerols and cholesteryl esters respectively within the enterocyte (Pfeffer et al. 1977). 


\section{CHYLOMICRON FORMATION}

Chylomicrons contain a core of triacylglycerols and cholesteryl esters covered by a surface layer of phospholipids, cholesterol and apoproteins. Within the intestinal epithelial cells, absorbed free fatty acids, monoacylglycerols and cholesterol are re-esterified and packed within a monolayer of phospholipids and apoproteins to form the chylomicron. After crossing the enterocyte membrane, free fatty acids are bound to a specific fatty acid binding protein with a high affinity for long chain unsaturated fatty acids.

Fatty acid binding protein prevents accumulation of potentially toxic unbound fatty acids within the cell (Ockner \& Manning, 1974). Resynthesis of triacylglycerols occurs in the endoplasmic reticulum of the enterocyte from the CoA-activated absorbed fatty acids and glycerol. This involves the esterification of acyl-CoA and utilizes two alternative pathways - the glycerol-3-phosphate pathway and the monoacylglycerol pathway. In most tissues, including liver and adipose tissue, the glycerol-3-phosphate pathway is the most important route for the synthesis of triacylglycerols, whereas in the enterocyte most triacylglycerol synthesis proceeds through the monoacylglycerol pathway.

Up to ninety percent of triacylglycerols in intestinal mucosa are formed through the monoacylglycerol pathway provided monoacylglycerols are available, as is the case following a fatty meal (O'Doherty \& Kuksis, 1974). The $s n-2$ monoacylglycerols, the major products from the action of pancreatic lipase in the intestinal lumen, are absorbed into the enterocyte where they are acylated to $s n$-1,2-diacylglycerols or $s n$-2,3-diacylglycerols and eventually to triacylglycerols. The enzymes necessary for triacylglycerol biosynthesis, i.e. long chain fatty acid: $C O A$ ligase $(E C 6.2 .1 .3)$, monoacylglycerol transferase and diacylglycerol transferase $(E C 2.3 .1 .20)$ are abundant and located on the smooth endoplasmic reticulum of the enterocyte (Shiau et al. 1980).

Cholesteryl esters and cholesterol are derived either from synthesis de novo in the enterocyte or from cholesterol absorbed from the intestinal lumen. The fraction of cholesterol more relevant to postprandial lipaemia is believed to be that derived from food intake (Durrington, 1989). This fraction of cholesterol is mostly re-esterified within the enterocyte. Acyl-Co-A cholesterol acyl transferase is an important enzyme in this process.

Phosphatidylcholine (lecithin) is the major phospholipid of chylomicrons. Acyl groups of chylomicron phosphatidylcholine do not reflect the composition of dietary fatty acids as is the case for triacylglycerols. The enterocyte can synthesize phosphatidylcholine by acylating lysophosphatidylcholine, absorbed from the lumen after digestion of phosphalidylcholine.

The enterocytes are capable of synthesizing apolipoproteins B-48, A-I and A-IV (apo B48 , etc.) which are combined with the intestinal lipids to form chylomicrons. The other apolipoproteins in circulating chylomicrons, i.e. apo CII, CIII and apo E, appear to be acquired by the chylomicron after release by the enterocyte.

The major apolipoprotein of chylomicrons is apo B (B-48). Apo B is synthesized in the rough endoplasmic reticulum, transferred to the smooth endoplasmic reticulum and incorporated into nascent chylomicrons. These move to the Golgi cisternae and vesicles, and undergo glycosylation prior to exocytosis from the cell membrane. Unlike other apoproteins apo B-48 remains within the core of the chylomicron from the time of formation of the particle in the smooth endoplasmic reticulum until uptake and removal by the liver. Apo A-I originates in the intestine and has been demonstrated in the enterocyte of man. It is not derived from the circulation through filtration. In the postabsorptive state, apo A-I exists in enterocytes and lamina propria, mostly in the free form. In mesenteric lymph, all apo A-I is associated with lipoproteins (Imaizumi et al. 1978). Apo A-IV is the third major apoprotein of chylomicrons originating in the intestine. Apo A-IV appears to 
transfer from newly secreted chylomicrons to high density lipoproteins (HDL) and then into the lipoprotein free fraction of plasma (Lefevre et al. 1986).

The extent to which enterocyte apoprotein synthesis is regulated by chronic or acute dietary fat intake and/or by dietary fat type is not clear. Studies carried out in animals suggest that sustained changes in acute transmucosal triacylglycerol flux or in background dietary fat intake have no effect on the synthesis of apo AI and apo B-48 (Davidson et al. $1986,1987)$. No studies have yet been conducted in man.

The size and composition of chylomicrons depend on the fat content of the meal ingested. Ingestion of small quantities of fat or phospholipids results in production of small chylomicrons similar to those produced in the fasted state. Small chylomicrons can be found during both the fasted and postprandial state and serve to transport endogenous lipids derived from the intestinal lumen and thus, generally, are not the particles causing postprandial lipaemia. Because there is one apo B-48 molecule for each chylomicron particle, the production of apo B-48 is likely to be a determinant of chylomicron size, with large high fat meals resulting in the formation of large low density chylomicron particles. The fatty acid composition of the meal will also determine chylomicron size, with PUFA producing larger chylomicrons than meals containing saturated fatty acids (Levy et al. 1991).

\section{POSTPRANDIAL CHYLOMICRON METABOLISM}

In the postprandial phase, chylomicrons are poured into the intestinal lymph, pass through the thoracic duct and enter the general circulation through the subclavian vein to cause postprandial lipaemia. Chylomicrons are the largest lipoprotein species with diameters ranging from 80 to $500 \mathrm{~nm}$, density $<0.96 \mathrm{~g} / \mathrm{ml}$, and flotation rates (Sf) $>400$. Chylomicrons begin to appear in the plasma within 60 min of ingestion of fat with the major part of the triacylglycerol component usually removed from circulation within $6-8 \mathrm{~h}$ after meal ingestion.

After secretion from the enterocyte and following their entry into the systemic circulation, chylomicrons acquire apo CII, CIII and apo E. These surface components are transferred to chylomicrons from HDL along with free and esterified cholesterol and phospholipids. Some apo AI and A-IV is also transferred from chylomicrons onto HDL at this stage. Apo CII and CIII are transferred rapidly, followed by apo E (Sherrill et al. 1980). The $C$ apoproteins are synthesized in the liver and to a lesser extent in the gut. Apo $\mathrm{CII}$ and CIII are intimately involved in the postprandial processing of both chylomicrons and very low density lipoproteins (VLDL) (see below) but no known role has yet been assigned to apo CI in lipoprotein metabolism. Apo $\mathrm{E}$ is mostly synthesized in the liver but also in extrahepatic tissues, including the intestine, brain, muscle, ovaries, kidney, spleen and adrenals. Its major role seems to be the targeting of the chylomicron remnant (the product of chylomicron triacylglycerol hydrolysis) for the receptor, serving as a ligand for remnant removal by the liver.

The first step in the catabolism of chylomicrons involves the action of lipoprotein lipase (EC 3.1.1.34) located in extrahepatic tissues, resulting in the formation of triacylglycerol depleted particles termed 'remnants'. The subsequent step in chylomicron catabolism involves a hepatic receptor mediated removal of chylomicron remnants.

\section{CHYLOMICRON HYDROLYSIS AND LIPOPROTEIN LIPASE}

Once the chylomicron has acquired apo CII it is capable of activating lipoprotein lipase, the enzyme responsible for the hydrolysis of triacylglycerols in chylomicron and VLDL particles. Apo CII acts as a co-lipase increasing the interaction of the enzyme with the 
substrate at the interface of the lipoprotein. Not all lipoprotein lipase found in tissues participates in triacylglycerol catalysis. Only that fraction of enzyme protein, the so-called functional lipoprotein lipase which is localized on endothelial surfaces of blood vessels, has contact with circulating triacylglycerol-rich lipoproteins (Eckel, 1989).

Because this enzyme is the rate limiting step in triacylglycerol hydrolysis its activity is an important determinant of the extent and duration of postprandial lipaemia. Since hydrolysis by lipoprotein lipase is the initial event in the uptake of triacylglycerol fatty acid by tissues, the enzyme also controls the availability of an important cellular fuel. Lipoprotein lipase is located on the vascular endothelium of tissues with a high requirement for fatty acids, such as skeletal and cardiac muscles, adipose tissue and mammary gland. Insulin has a profound effect on lipoprotein lipase activity in adipose tissue, promoting both synthesis and release of the enzyme (Spooner et al. 1979).

Conversely, skeletal muscle lipoprotein lipase appears to be inhibited by insulin so that increased skeletal muscle lipoprotein lipase activity occurs during the postabsorptive period when insulin concentrations have returned to fasting levels (Cryer et al. 1976).

Hydrolysis of chylomicron triacylglycerols results in smaller, relatively protein enriched particles with a redundant surface coating of free cholesterol and phospholipid. As the core triacylglycerol component becomes progressively smaller, surface materials (phospholipids, cholesterol and apoproteins CII and CIII) are transferred to HDL to maintain the stability of the chylomicron particle. The transfer of apo CII, together with increasing inaccessibility of core triacylglycerols for the lipoprotein lipase active site, results in cessation of further triacylglycerol removal. The apo B-48 present from the time of synthesis in the enterocyte remains tightly bound within the core of the chylomicron particle. Apo E also remains within the chylomicron and regions of its structure are exposed allowing recognition of the particle by two hepatic lipoprotein receptors. These are the remnant receptor, also termed the apo E receptor, and the low density lipoprotein (LDL) or apo B-100/E receptor.

\section{CHYLOMICRON REMNANT CLEARANCE}

Extraction of chylomicron remnants from the circulation occurs in the liver and is accomplished mainly by high affinity receptor mediated process(es). As discussed below, there is evidence for a specific hepatic receptor which binds remnants that contain apo $\mathrm{E}$ (chylomicrons and VLDL), which is separate and distinct from the LDL or B-100/E receptor. However the isolation and characterization of this receptor has proved elusive and until this is achieved its role in remnant removal must remain a putative one.

The existence of a specific chylomicron remnant receptor has been suggested by studies of normal rates of remnant binding to hepatic plasma membranes from subjects with familial hypercholesterolaemia who lack the LDL receptor. The chylomicron remnant receptor was first suggested to be genetically distinct from the LDL receptor in studies which showed that chylomicron clearance occurs normally in human subjects with homozygous familial hypercholesterolaemia. Sterol loading, which down-regulates the LDL receptor, does not affect the chylomicron remnant receptor on human macrophages. However, studies on the uptake and degradation of chylomicron remnants by the human hepatoma cell line, Hep G2, by Chen et al. (1991) indicated that chylomicron remnant uptake is regulated similarly to the LDL receptor. A monoclonal anti-LDL receptor blocked binding of chylomicron remnants to Hep G2 cells and the uptake process was regulated by factors which affect cholesterol synthesis.

Although this study of a human hepatoma cell line and experiments in mice seem to be at variance with the concept of a separate chylomicron remnant receptor (Choi et al. 1991), 
experiments in man indicate that variable expression of the LDL receptor does not produce significant differences in the magnitude of lipaemia, consistent with the hypothesis that chylomicron remnants are not regulated, predominantly, by the LDL receptor but by a separate apo E receptor (Herz et al. 1988). These authors have termed this receptor the $\mathrm{LDL}$ receptor-related protein.

Factors which appear to be important in regulating receptor mediated remnant removal include: the apo E phenotype, the activity of the hepatic triacylglycerol lipase, and the presence of apo CIII. Three isoforms of apo $E$ are commonly found in human populations and are referred to as E2, E3 and E4. The E3/E3 phenotype is most commonly found $(60 \%)$ with E2/E3 having a prevalence of approximately $23 \%$. The avidity of binding of apo $\mathrm{E}$ isomers to receptors is in the order E4 $>\mathrm{E} 3>\mathrm{E} 2$. Subjects homozygous for E2 have elevated leveis of chylomicron remnants (Type III hyperlipidaemia) and an increased risk of coronary artery disease.

There is increasing interest in the role of hepatic triacylglycerol lipase in mediating removal of chylomicron and VLDL remnants and in the hormonal and dietary factors which may determine the activity of this enzyme. Griglio et al. (1992) elucidated the role of hepatic triacylglycerol lipase in chylomicron remnant removal and suggested that phospholipolysis of chylomicron remnants may be an obligatory metabolic process prior to uptake by the remnant receptor. It is therefore of interest that apo CIII has been shown to inhibit hepatic triacylglycerol lipase (Kinnunen \& Ehnholm, 1976) and also to impair remnant recognition by the hepatocyte remnant receptor (Van Berkel et al. 1983). Other suggestions are that Apo CIII appears either to displace apo $E$ or to interact with and obscure the apo E ligand. For these reasons it is proposed that the binding of the chylomicron remnant to hepatic receptors requires prior dissociation of apo CIII. Since removal of apo CIII occurs onto $\mathrm{HDL}$, this provides a further example of the close interaction between the pathways of metabolism of HDL and triacylglycerol-rich lipoproteins and one which may be of significance to the clearance of chylomicron remnants.

\section{REVERSE CHOLESTEROL TRANSPORT, CHOLESTERYL ESTER TRANSFER PROTEIN AND TRIACYLGLYCEROL-RICH LIPOPROTEINS}

The rate of transport of $\mathrm{LDL}$ cholesterol to peripheral tissues generally exceeds tissue cholesterol requirements except during periods of active growth or tissue repair. Because most cells are unable to carry out oxidation of cholesterol, excess steroid must be returned to the liver for elimination in the bile. The return of cholesterol from the tissues is termed 'reverse cholesterol transport' and HDL plays a central role in this pathway, with the reaction catalysed by lecithin cholesterol acyl transferase $(E C 2.3 .1 .43)$ acting as the rate regulating step. The latter enzyme catalyses the transfer of a fatty acid from position $s n-2$ of phosphatidylcholine to cholesterol.

There is also now evidence that a considerable proportion of the cholesterol initially transferred from peripheral cells onto HDL ultimately returns to the liver via chylomicron and VLDL remnant particles and that during this latter transfer there is a reciprocal enrichment of $\mathrm{HDL}$ particles with triacylglycerols. This reciprocal crossing over of cholesteryl esters and triacylglycerols between triacylglycerol-rich lipoproteins and HDL is catalysed by an enzyme complex, cholesteryl ester transfer protein, also called lipid transfer protein.

Until the mid 1970s it was generally thought that cholesteryl esters, because of their insolubility in the aqueous phase, could not transfer between lipoprotein particles. With the 


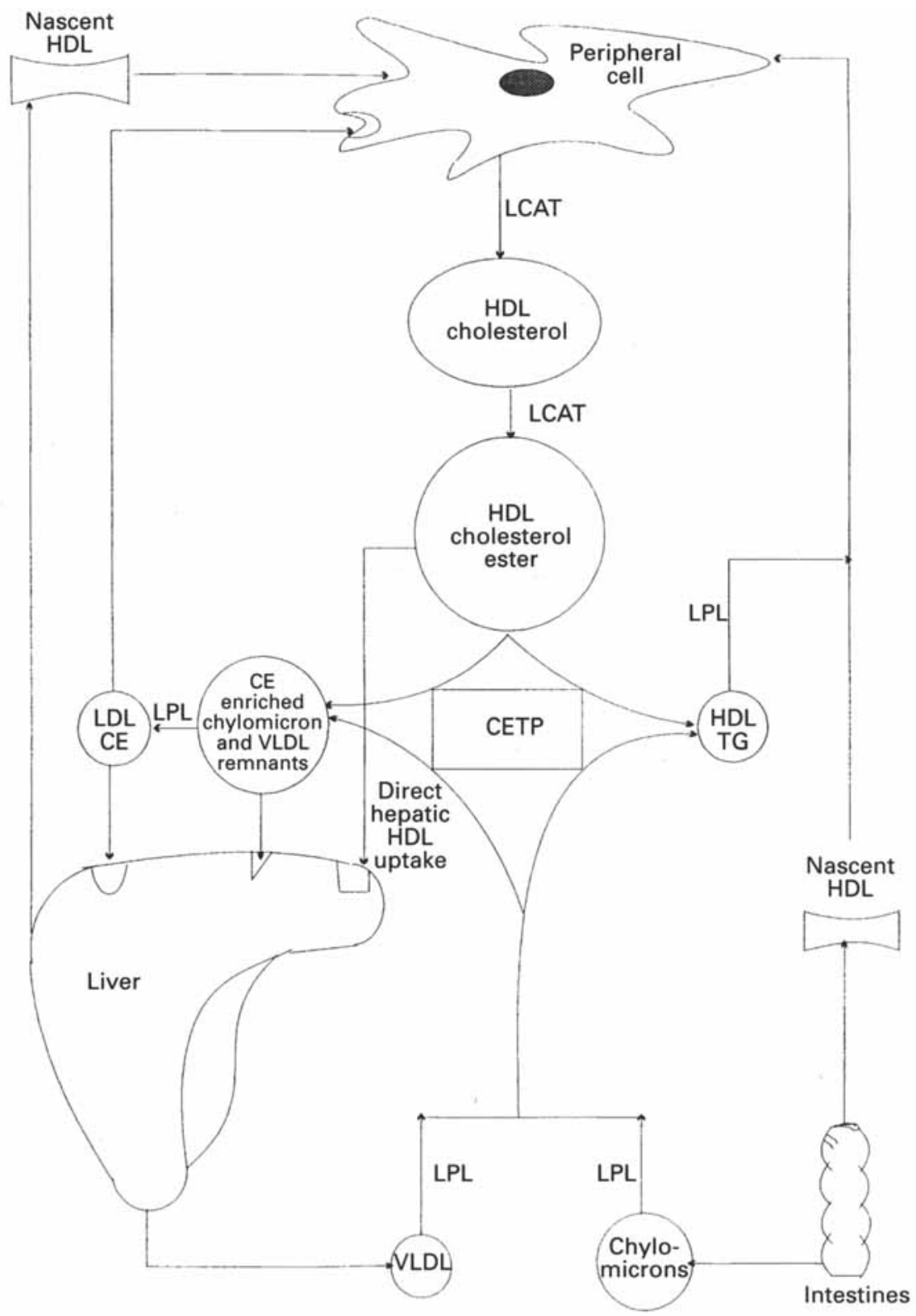

Fig. 1. A representation of the dynamics of lipoprotein lipid transfer mechanisms in the circulatory system. CE, cholesteryl ester; CETP, cholesteryl ester transfer protein; HDL, high density lipoprotcins; LCAT, lecithin cholesterol acyl transferase; LDL, low density lipoproteins; LPL, lipoprotein lipase; TG, triacylglycerol; VLDL, very low density lipoproteins.

discovery of cholesteryl ester transfer protein in 1976, the mechanism for movement of cholesteryl esters and triacylglycerols between lipoproteins was established.

A diagrammatic representation of the lecithin cholesterol acyl transferase and cholesteryl ester transfer protein catalysed reactions is shown in Fig. 1. There is some evidence that cells loaded with cholesteryl ester express receptors for HDL (apo AI receptors) which 
activate the hydrolysis of the fatty acid from cholesteryl esters and subsequent efflux of free cholesterol from the cell. Free cholesterol is acquired by nascent HDL (HDL3) from peripheral cells and esterified by lecithin cholesterol acyl transferase, which together with addition of surface materials from chylomicrons and VLDL result in the formation of the less dense HDL2. Some cholesterol is taken up directly into HDL2 by the liver but most is transferred onto chylomicron and VLDL particles by the action of cholesteryl ester transfer protein.

In man, at least $80 \%$ of the cholesteryl esters formed initially on HDL are transported to other lipoproteins, and estimates suggest that at least $1500 \mathrm{mg}$ cholesterol is metabolized daily via this route (Durrington, 1989). This interaction between triacylglycerol-rich lipoproteins and HDL therefore provides an important pathway of cholesterol metabolism and one which has received insufficient attention in the dietary lipid-lipoprotein-coronary artery disease hypothesis. The significance of disturbances in this pathway to the aetiology of atherogenesis is discussed in more detail in section 5 , but it is clear from the above account that perturbations which lead to increased transfer of cholesterol onto chylomicrons (and VLDL) and/or those which result in impaired removal of the transporting vehicle, the chylomicron remnant, will result in accumulation of cholesterol enriched remnant particles in circulation. In view of evidence for the atherogenicity of this particle (Mahley, 1982), factors which contribute to adverse concentrations of remnants within the circulation appear to require investigation.

Situations which lead to periods of marked postprandial lipaemia resulting from increased synthesis, or impaired clearance, of chylomicrons might be expected to result in increased transfer of cholesteryl esters into chylomicrons. In the following section some of the factors which influence postprandial lipaemia are discussed and particular emphasis is placed on the role of dietary factors, notably dietary fat, on postprandial lipoprotein metabolism.

\section{FACTORS INFLUENCING POSTPRANDIAL LIPAEMIA}

Studies of postprandial lipaemia are made difficult by the need for prolonged periods of postprandial investigation since chylomicrons produced from a single meal may remain in circulation for up to $12 \mathrm{~h}$ following meal consumption. Interpretation of published results is complicated by the fact that a majority of studies have measured concentrations of total plasma triacylglycerols, rather than separate determinations of the chylomicron and VLDL triacylglycerol fractions. This makes the relative contributions of exogenous and endogenous lipoproteins to postprandial lipaemia difficult to estimate. Furthermore, as discussed in the previous section, the postprandial lipoprotein particles of particular interest in relation to atherogenesis are the chylomicron remnants. At present there is no satisfactory method for estimating the concentrations of these particles in the postprandial circulation. Because of their similar densities, chylomicron remnants and VLDL particles cannot be separated by ultracentrifugation. The most commonly used approach is an indirect one involving oral dosing with retinyl palmitate, a method which relies on the assumption that retinyl palmitate administered with a meal is secreted with chylomicrons and remains within the chylomicron or chylomicron remnant particle until its removal by the hepatic receptor (Berr \& Kern, 1984).

However, recent evidence for significant exchange of retinyl palmitate with other circulating lipoproteins and marked resecretion of retinyl palmitate in newly formed LDL raise doubts about the validity of findings which have employed this method (Krasinski et al. 1990). Interpretation of the significance of some of the findings described below must be made in the context of these methodological limitations. 


\section{DIETARY INFLUENCES ON POSTPRANDIAL LIPOPROTEINS}

\section{Effect of meal composition}

As might be expected, increasing the fat content of standard test meals results in more marked postprandial lipaemia. Cohen $e t$ al. (1988) examined the effect of ingesting 40, 80 or $120 \mathrm{~g}$ fat (as cream) in 12 normotriacylglycerolaemic men and found plasma triacylglycerol concentrations after $8 \mathrm{~h}$ of $2 \cdot 8,5.7$ and $8.0 \mathrm{mmol} / 1$ respectively. It must be noted however that these studies do not represent the normal physiological situation in which fat is consumed in the form of mixed meals in combination with varying amounts and types of carbohydrates and proteins. A recent study by Chen and co-workers (1992), employing the retinyl palmitate loading test, compared chylomicron and chylomicron remnant responses to isocaloric low and high fat test meals in subjects with non-insulin dependent diabetes. Although postprandial chylomicron triacylglycerol responses were higher following the high fat meal, the extents of the differences were modest considering the marked differences in fat content of the two meals $(25 \% .45 \%$ fat as energy). Furthermore chylomicron remnant concentrations were actually higher following the low fat high carbohydrate meal than following the high fat moderate carbohydrate meal.

This particular finding is important for two reasons, firstly because it illustrates a potentially adverse effect of a low fat diet in non-insulin dependent diabetes, and secondly because it suggests that improved clearance of chylomicron triacylglycerols is not necessarily associated with improved clearance of the potentially atherogenic species, the chylomicron remnant.

Further studies are required to investigate modulatory effects of other macronutrients on postprandial lipaemia. Although Cohen and colleagues found that the protein content of standard test meals did not influence postprandial lipaemia, they have reported marked differences according to meal carbohydrate composition (Cohen, 1989; Cohen \& Berger, 1990). Early work by Albrink et al. (1958) showed that dietary glucose significantly reduced the postprandial hyperlipaemia following fat intake, and glucose has been found to lead to lower postprandial plasma triacylglycerol levels than sucrose after fat ingestion (Mann $e t$ al. 1971). More recently, Cohen \& Schall (1988) studied the effect of $50 \mathrm{~g}$ of either fructose, sucrose or glucose on postprandial lipid metabolism following the consumption of $100 \mathrm{ml}$ cream $(40 \mathrm{~g}$ fat). Fructose greatly augmented the postprandial hyperlipidaemia phase compared to the control diet without carbohydrate, while sucrose had no effect and $50 \mathrm{~g}$ glucose diminished the response. Recent work by the same group (Cohen \& Berger, 1990) indicated that some of these effects may be related to different osmotic effects of simple carbohydrates in the gut. Thus urea at the same osmotic strength as the $50 \mathrm{~g}$ glucose load had as strong an attenuating effect on postprandial triacylglycerols as did $50 \mathrm{~g}$ glucose.

There are surprisingly few studies which have reported effects of non-starch polysaccharide on postprandial lipaemia in human subjects and none which have investigated chylomicron remnant response to varying non-starch polysaccharide intake. One recent study found no effect of guar gum on postprandial plasma triacylglycerol response in males, whilst in females the inclusion of guar gum was found to augment both the extent and duration of lipaemia (Redard et al. 1990). In a recent study in which $10 \mathrm{~g}$ guar gum was added to a normal meal a small delay in the time to peak plasma triacylglycerol response was observed, which suggests attenuating effects of soluble nonstarch polysaccharide in triacylglycerol digestion and/or absorption (Lovegrove et al. 1993). 


\section{Effect of dietary fatty acid composition}

Studies of effects of modifying the fatty acid composition of both standard test meals and background diets show that acute and habitual dietary fatty acid intake can markedly influence postprandial chylomicron triacylglycerols and remnant responses. Early work by Heimberg et al. (1974) showed that the postprandial plasma triacylglycerol response to the ingestion of safflower oil was significantly higher than that to coconut oil. It would, however, be wrong to consider this as a fair comparison of a polyunsaturated and a saturated fat since coconut oil has a reasonably high proportion of medium chain fatty acids which would be absorbed and transported via the hepatic portal vein to the liver. Hence the slower and smaller postprandial response to coconut oil ingestion may reflect a different pathway of metabolism for this atypical dietary fat. Harris et al. (1988) observed that the ingestion of a meal rich in saturated fat (cocoa butter, peanut oil) produced a greater postprandial response in plasma triacylglycerols than a meal rich in $n-6$ polyunsaturates (safflower oil, maize oil).

In a recent comparison of postprandial chylomicron triacylglycerol responses to standard test meals of different fatty acid compositions, Zampelas and co-workers (1993a) found that lipaemic responses were greatest to a mixed oil meal (fatty acid composition similar to that of current UK intake) and least to a fish oil meal, with the triacylglycerol response to maize oil intermediate between the two. Furthermore they observed higher postheparin lipoprotein lipase activity in plasma obtained $12 \mathrm{~h}$ after the fish oil meal than following the other two meals (unpublished findings). These data suggest that triacylglycerol lowering effects of acute n-3 fatty acid ingestion may be due to increased clearance of chylomicrons containing a high proportion of n-3 PUFA. It is important to note that in this study no differences in chylomicron retinyl palmitate concentrations were found in response to the three meals, suggesting that whilst triacylglycerol clearance may be accelerated, clearance of chylomicron particles themselves may be unaffected by dietary fatty acid composition. However these findings may also be attributable to the unreliability of retinyl palmitate as a measure of chylomicron particles clearance since the same authors also measured chylomicron apo B-48 concentrations in response to fish oil and mixed oil diets and found marked attenuation of chylomicron apo B-48 levels following the fish oil meal (Peel et al. 1993).

Demacker and co-workers (1991) investigated effects on chylomicron triacylglycerol and apo B-48 response of increasing the PUFA content of the background diet for a period of two weeks and showed a marked reduction in the area under the apo B-48 and chylomicron triacylglycerol response curves on the PUFA diet compared with the usual background diet. Weintraub et al. $(1988 \mathrm{~b})$, in a series of experiments comparable to those of Harris $e t$ al. (1988), studied effects of modifying both habitual and acute dietary fatty acid intake.

Subjects were given one of three different experimental isocaloric diets: (i) saturated fat, (ii) n-6 PUFA, (iii) n-3 PUFA, each for a period of $25 \mathrm{~d}$. Towards the end of each dietary period two test meals were given on separate days, one rich in saturated, the other in polyunsaturated, fatty acids. The authors observed that where the pattern of habitual fat intake was one rich in saturated fatty acids, chylomicron and chylomicron remnant responses to saturated fatty acids and PUFA test meals were essentially similar. Where the habitual intake was one rich in $n-6$ polyunsaturates, postprandial responses to the $n-6$ polyunsaturated test meal were notably lower than to the saturated test meal. The highest response was seen when saturated fatty acids comprised both the habitual and acute load diet and this response was more than double that observed when a meal rich in n-6 PUFA was consumed by individuals following a habitual diet rich in n-6 PUFA.

Both these studies (Harris et al. 1988; Weintraub et al. 1988 b) were designed primarily 
to examine the effect of fish oils rich in n-3 PUFA on postprandial lipid metabolism. Plasma and chylomicron triacylglycerol responses and chylomicron remnant responses to both saturated fatty acids and PUFA test meals were markedly diminished with chronic ingestion of an n-3 enriched diet. Postprandial responses were most markedly attenuated in subjects given an acute test meal enriched with n-3 PUFA when their background diets also contained the n-3 PUFA. Williams and co-workers (1992) also showed that supplementation of the habitual diets of normal subjects with $10 \mathrm{~g}$ per day MaxEPA $(\sim 3 \mathrm{~g} \mathrm{n}-3$ PUFA) resulted in a $40 \%$ reduction in plasma triacylglycerol response to a standard meal rich in saturated fatty acids.

These data support the conclusion that whilst the postprandial lipaemic response to an acute PUFA test meal is generally lower than that to a saturated fatty acids meal, the effect is most marked when n-3 PUFA are fed. Long term consumption of PUFA diets results in attenuation of the lipaemic response with both n-3 and n-6 PUFA, the effect being more marked and more consistent with the former. The fact that more consistent triacylglycerol lowering effects of PUFA-rich diets are seen when these diets are fed chronically and, in some studies, appear to be independent of the nature of the fat fed in the acute test meal, suggests that hypotriacylglycerolaemic effects of PUFA-rich diets cannot simply be due to these fatty acids acting as better substrates for lipoprotein lipase. In this respect the findings reported by Murphy and co-workers (1993) of increased adipose tissue lipoprotein lipase mRNA in animals fed a fish oil diet are of interest and suggest that dietary fatty acids may influence the gene expression of this enzyme. However the triacylglycerol-lowering effects of fish oil are generally accepted to be associated with reduced hepatic output of VLDL in man (Nestel et al. 1984) and more recent studies in non-human primates have shown that the reduction in hepatic VLDL output is not associated with reduced apo B-100 secretion (Parks et al. 1990).

No studies of effects of monounsaturated fatty acid intake on chylomicron and chylomicron remnant metabolism have been conducted in man and are urgently required in view of recent emphasis on the potential health benefits of increasing the proportion of these fatty acids in the diet. Brouwer et al. (1993) in comparing responses to intravenous infusions of olive and soyabean oils showed slower rates of triacylglycerol clearance, lower levels of apo CII and lower rates of hepatic triacylglycerol lipase activity in the case of the olive oil infusion.

Lower activity of hepatic lipase suggests possible adverse effects of olive oil on rates of chylomicron remnant clearance and warrants further study with respect to effects of orally administered olive oil and oleic acid enriched diets in man.

\section{PHYSIOLOGICAL FACTORS INFLUENCING POSTPRANDIAL LIPOPROTEINS}

Cohn et al. (1988) have examined age and sex as factors influencing postprandial lipid response. Females showed a lower response at all ages and younger subjects showed a much lower response than older subjects. However, these and other authors (Nestel, 1964; Grundy \& Mok, 1976) have shown markedly consistent correlations between the basal (fasting) plasma triacylglycerol level and the extent of postprandial lipaemia. In the study of Cohn and co-workers (1988), differences between subjects due to age, and between the sexes, largely disappeared when the effect of fasting plasma triacylglycerols on postprandial lipaemia was examined.

Effects of both intensive and moderate forms of exercise on postprandial lipoprotein metabolism have also been investigated. The chronic effects of exercise have been studied 
by Weintraub et al. (1988a). Physical exercise conditioning significantly reduced the postprandial chylomicron and chylomicron remnant responses to standard meals and there were also increases in postheparin lipoprotein lipase and hepatic triacylglycerol lipase activities of plasma. Cohen et al. (1989) compared highly trained endurance athletes and sedentary controls, matched for body weight and fasting plasma triacylglycerol levels. The level of postprandial hyperlipaemia after $8 \mathrm{~h}(\mathrm{mmol}$ triacylglycerol/l) was significantly higher in the sedentary men compared to the endurance athletes $(2.6 v .1 .5$ following an intake of $40 \mathrm{~g}$ fat and $6 \cdot 1$ v. 2.5 following $140 \mathrm{~g}$ fat).

They concluded that the major effect of exercise on postprandial lipaemia was an increased rate of clearance of lipids from plasma although there may also be an additional effect of reduced competition from hepatic lipoproteins rich in triacylglycerols.

Although a study of moderate exercise in the immediate postprandial phase showed no effect on the 3-h plasma triacylglycerol response to a fat meal in normal adult subjects (Welle, 1984), a recent study suggests that modest exercise prior to meal consumption may influence postprandial lipaemia. Aldred and co-workers (1993) observed a $30 \%$ reduction in peak triacylglycerol response to a standard test meal in normal adult subjects who carried out moderate exercise for $2 \mathrm{~h}$ on the day prior to the test meal, compared with their responses after a control (no exercise) day.

The activity of lipoprotein lipase may be an important determinant of the variation in the postprandial lipid response with age, sex and fasting triacylglycerol levels and increased lipoprotein lipase activity may also explain the blunted postprandial lipaemia associated with acute and chronic exercise. Weintraub et al. $(1987 a, b)$ have shown that the activities of lipoprotein lipase are significantly higher in young subjects (19-28 years) compared to older subjects (40-72 years). They also showed a tendency towards higher activity of lipoprotein lipase in women than men, although the difference was not statistically significant. The same group showed that plasma lipoprotein lipase was significantly increased following exercise conditioning (Weintraub et al. 1988a). It is clear that variations in lipoprotein lipase activity may be responsible for a considerable proportion of the variation in postprandial lipaemia which is seen between individuals and in response to different background diets. Further studies of dietary and hormonal influences on the regulation of lipoprotein lipase activity and gene expression in human tissues are required.

\section{THE NATURE OF THE POSTPRANDIAL RESPONSE TO INGESTION OF LIPID}

In general terms, the consumption of fat is followed by a rise in triacylglycerol-rich lipoproteins. This pattern of a rapid rise and fall in triacylglycerol-rich lipoproteins, resulting in a single peak, is widely accepted as the physiological response to fat ingestion. Recently, however, several authors have shown that, in addition to the accepted monophasic response, there also exist both biphasic and triphasic patterns. Cohn et al. (1988), in a study involving 22 healthy subjects, found that only 5 had one peak of postprandial triacylglycerol-rich lipoprotein while 11 (i.e. $50 \%$ ) had two and 7 had three. Similar results have been obtained by Olefsky et al. (1976) and Kashyap et al. (1983). The secondary responses generally occurred some $8 \mathrm{~h}$ after the test meal and the tertiary response at about $10 \mathrm{~h}$. These multiphasic responses occur after the ingestion of a single fatcontaining meal and are not easily explained.

Cohn et al. (1989) have suggested a number of possible factors which might be involved. These include variations in gastric emptying, gastrointestinal motility, the rate of fat digestion, differentials in the absorption and transport of fat between the proximal and 
distal small intestine, or fluctuations in the availability of newly synthesized phospholipid or apolipoproteins. These authors also refer to the interesting data of Mansbach \& Parthasarathy (1982) who have demonstrated two pools of mucosal triacylglycerols. One pool derives its triacylglycerol glycerol from absorbed glycerol while the other derives its glycerol from de novo synthesis. The former may contribute more to earlier peaks and the latter to the subsequent secondary rise in plasma triacylglycerols.

Williams and co-workers noted that whilst they consistently observed biphasic triacylglycerol responses to meal ingestion when test meals were given in the early evening approximately $5 \mathrm{~h}$ after a standard lunch, similar responses were not observed when meals were given after an overnight fast (Williams et al. 1992; Zampelas et al. 1993b). They have proposed that the early rise in triacylglycerol concentrations which they observed approximately $1 \mathrm{~h}$ after an evening meal may represent a secondary influx of undigested triacylglycerols from the meal taken prior to the test meal and provoked by increased gastrointestinal activity in response to the test meal. Evidence for this proposal has been provided by recent studies in which they labelled standard test meals with retinyl palmitate and measured postprandial chylomicron triacylglycerol, apo B-48 and retinyl palmitate concentrations. A single retinyl palmitate peak was observed at approximately $5 \mathrm{~h}$ after the meal, whereas both triacylglycerols and apo B-48 showed distinct biphasic responses with peaks occurring at 1 and $5 \mathrm{~h}$ after the meal (Peel et al. 1993). These data suggest that the second peak represents triacylglycerols ingested with the test meal, whilst the first represents previously ingested triacylglycerols. These authors have speculated that multipeaks observed by other workers may reflect secondary and tertiary influxes of fat from the test meal provoked, for example, by consumption of fluid at regular periods during the studies.

Further information on effects of repeated fat ingestion throughout the day on postprandial lipid responses has been provided by a number of groups. Olefsky et al. (1976) gave a $1000 \mathrm{kcal}$ meal containing $35 \%$ energy from fat to 41 subjects over a 12 -h period: $20 \%$ at $08.00 \mathrm{~h}, 40 \%$ at $12.00 \mathrm{~h}$ and $40 \%$ at $19.00 \mathrm{~h}$.

Two triacylglycerol peaks were observed, one at $1 \mathrm{~h}$, the other at $5 \mathrm{~h}$ postprandially. Kay et al. (1980) administered a $136 \mathrm{~g}(50 \%$ energy) fat meal as a single bolus followed by five 2 -h intakes of protein and carbohydrate to provide a total intake of $2500 \mathrm{kcal}$. A second group received fat, protein and carbohydrate in six equally spaced meals of similar composition. The single fat meal produced a single triacylglycerol peak at $3 \mathrm{~h}$ which declined thereafter in a linear fashion. The divided fat meal resulted in a lower and later peak $(6-9 \mathrm{~h})$ which again declined in a linear manner. Although these studies are of value in understanding effects of repeated meals on the nature and extent of postprandial lipaemia, further studies are needed in which both chylomicron triacylglycerol and remnant responses are evaluated and with subjects ingesting standard meals at normal meal times throughout a $16-\mathrm{h}$ day. There is a particular need to study effects of meal frequency on postprandial lipids, both by comparing groups with different patterns of intake and by altering the frequency of meal consumption in individuals.

\section{POSTPRANDIAL LIPAEMIA, ATHEROGENIC LIPOPROTEINS AND CORONARY ARTERY DISEASE}

The atherogenic potential of postprandial lipoproteins was postulated as early as 1979 . This has since been referred to as the 'Zilversmit hypothesis' (Zilversmit, 1979). According to this hypothesis, chylomicrons and their remnants, if enriched in dietary cholesterol rather than triacylglycerols, possess the potential to cause cholesterol deposition in the arterial 


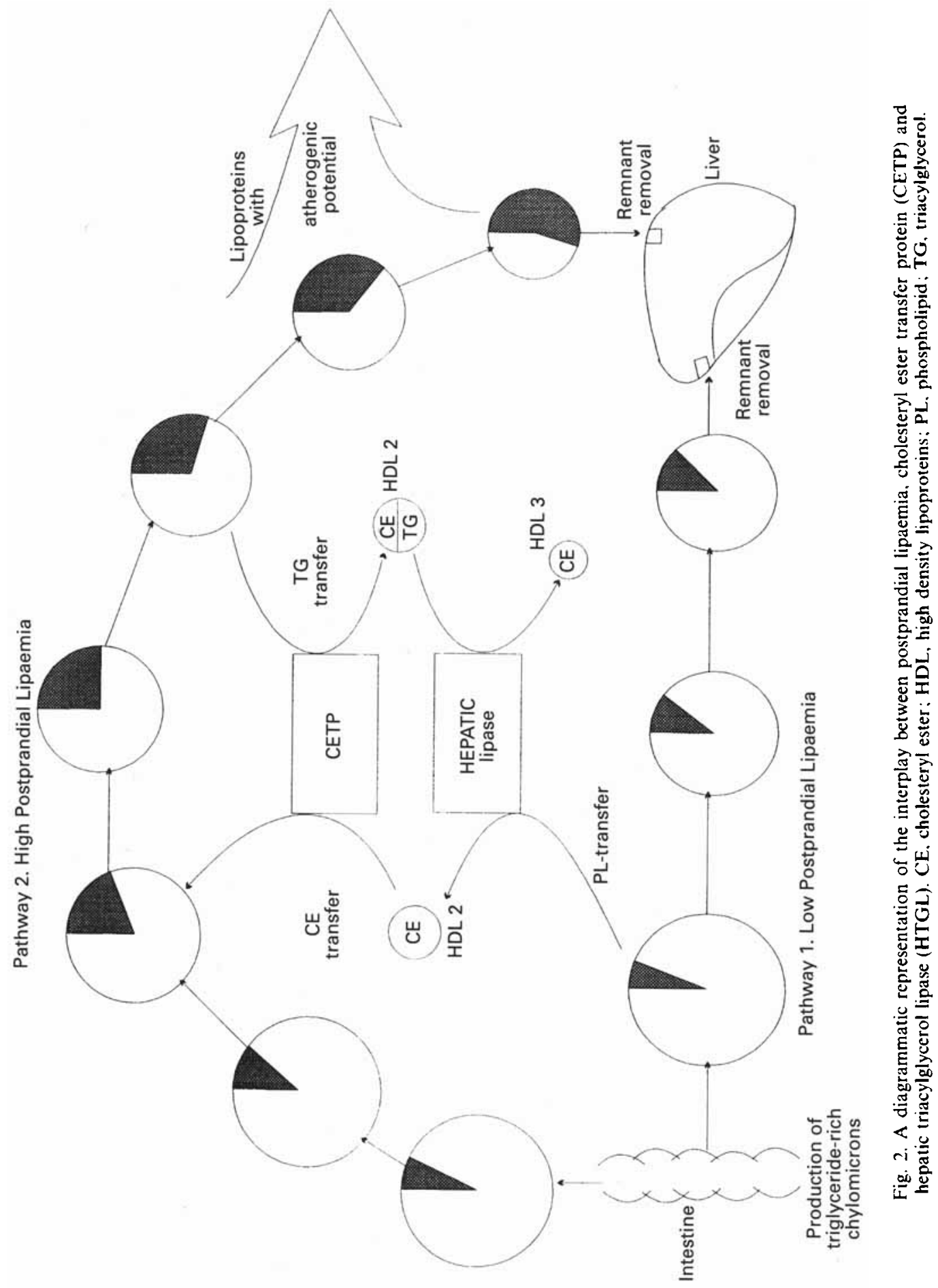


wall. This hypothesis has now been considerably extended to include consideration of the consequences of the cholesteryl ester transfer protein reaction and effects of this on the composition of other lipoproteins.

\section{MECHANISMS BY WHICH POSTPRANDIAL LIPAEMIA PREDISPOSES TO CORONARY ARTERY DISEASE}

As discussed on p. 166 the discovery of cholesteryl ester transfer protein showed that triacylglycerol-rich lipoproteins can be enriched with cholesteryl esters within the circulation by transfer of cholesteryl esters from HDL and this appears to be the major route by which cholesteryl esters are returned to the liver for excretion. Furthermore there is evidence that when triacylglycerol clearance is delayed, transfer of cholesteryl esters from LDL may also occur, with reciprocal exchange of triacylglycerols from chylomicrons or VLDL. Hence the enrichment of chylomicrons and VLDL with cholesteryl esters is also associated with progressive enrichment of both HDL and LDL with triacylglycerols. Triacylglycerols transferred to LDL and HDL are susceptible to hydrolysis by lipases, which reduce the size of these lipoproteins. The result is a preponderance of small LDL ('pattern B') and small HDL (HDL3), the 'atherogenic lipoprotein phenotype' described by Austin et al. (1990).

Because of these experimental findings and because of epidemiological evidence which supports a role for both remnant particles and the small dense LDL and HDL3 particles in coronary artery disease, a modified and more widely accepted view of the atherogenic potential of postprandial lipoproteins has developed in recent years, whereby triacylglycerol transport in general is considered potentially atherogenic. This concept has been labelled the 'triacylglycerol intolerance' hypothesis. According to this, a low triacylglycerol metabolic capacity in itself constitutes a handicap that imparts coronary artery disease susceptibility. In this extended version of the original hypothesis, coronary artery disease risk is not linked solely to delayed chylomicron remnant clearance in the postprandial state, but rather to impaired transport of triacylglycerol-rich lipoproteins both of intestinal and/or hepatic origin. Postprandial lipaemia is perhaps the most dominant phase of triacylglycerol transport, and thus measuring the magnitude of lipaemia is a realistic index of triacylglycerol metabolic capacity. The metabolic handicap which imparts an increased coronary artery disease risk is aptly termed 'impaired triacylglycerol tolerance' in order to distinguish it from fasting hypertriacylglycerolaemia and also demonstrates that a fat load test is required in order to unmask this condition. Impaired triacylglycerol tolerance typically leaves its mark on all lipoprotein classes: triacylglycerol enriched HDL, low HDL2-cholesterol, cholesteryl ester enriched intermediate density lipoproteins (IDL) and chylomicron remnants and small dense LDL particles (pattern B).

Fig. 2 is a diagrammatic representation of the interplay between postprandial lipaemia, cholesteryl ester transfer protein and hepatic triacylglycerol lipase. In individuals with effective triacylglycerol metabolism (Pathway 1, low postprandial lipaemia), triacylglycerolrich lipoproteins do not accumulate and do not become significantly enriched in cholesteryl esters (shaded segments). Chylomicron derived phospholipids are transferred to HDL2 and hepatic lipase serves to remove from these particles the excess phospholipid such that the renewed HDL2 continues to serve as a phospholipid acceptor. In individuals with a high postprandial lipaemia (pathway 2), chylomicrons accumulate in circulation for a prolonged time, resulting in their extensive enrichment with cholesteryl esters. These cholesteryl ester enriched remnants may then be deposited at sites resulting in atheromata. The cholesteryl ester withdrawn from HDL is replaced by triacylglycerol, whose hydrolysis leads to accumulation of small dense HDL3. 
Table 1. The atherogenic lipoprotein phenotype

\begin{tabular}{ll}
\hline \hline Presence of triacylglycerol enriched HDL particles \\
Low HDL2 cholesterol \\
Cholesteryl ester enriched IDL and chylomicron remnants \\
Increased small HDL (HDL3) \\
Increased small dense LDL particles ('pattern B') \\
\hline \hline
\end{tabular}

Further development of the 'triacylglycerol intolerance' hypothesis will depend upon the direct demonstration, in vivo, of a quantitative relationship between triacylglycerol metabolic capacity, which determines the concentration and plasma residence time of triacylglycerol-rich lipoproteins, and the degree of their enrichment with cholesteryl esters. Working with VLDL preparations in vitro, Mann et al. (1991) showed that as the triacylglycerol concentration was raised to $\sim 3 \mathrm{mmol} / \mathrm{l}$, the rate of enrichment of the particles with cholesteryl esters was proportional to the concentration of lipoprotein particles. Up to this concentration, transfer activity was independent of the concentrationof cholesteryl ester donor particles and cholesteryl ester transfer protein activity. At higher triacylglycerol levels, cholesteryl ester transfer protein activity became rate limiting, and the rate of cholesteryl ester transfer to triacylglycerol-rich lipoproteins reached a plateau with respect to triacylglycerol concentration. Extrapolating these findings to conditions in vivo, it is known that differences in triacylglycerol metabolic capacity are very large even among normolipidaemic individuals, so that the associated differences in the amount of cholesteryl ester transferred to triacylglycerol-rich lipoproteins daily may be equally large and is calculated to be of the order of gram quantities of cholesteryl ester.

In the remainder of this review evidence will be presented from experimental studies to support the concept of chylomicron remnants as atherogenic particles, and from epidemiological studies to support the involvement of triacylglycerol intolerance in general, and remnants in particular, in the aetiology of coronary artery disease.

\section{ATHEROGENICITY OF CHYLOMICRON REMNANTS}

Triacylglycerol-rich lipoproteins, especially chylomicron remnants, have been shown to interact with receptors present on cells other than hepatocytes. In particular, uptake of remnants by macrophages is capable of overloading these cells with triacylglycerol and cholesterol leading to the formation of foam cells (Goldstein et al. 1980). Van Lenten $e t$ al. (1985) demonstrated that human macrophages possess chylomicron remnant receptors, which can be distinguished from the LDL receptor. Several studies have shown that macrophages incubated in the presence of $\beta$-VLDL show marked accumulation of cholesteryl ester (Zilversmit \& Hughes, 1973; Chung et al. 1989; Huff et al. 1991). BetaVLDL comprise the remnants of both chylomicrons and VLDL obtained from animals fed high levels of fat and cholesterol or from patients with type III hyperlipoproteinaemia. The latter possess the E2/E2 apolipoprotein phenotype which results in impaired clearance of postprandial triacylglycerol-rich lipoprotein. While $\beta$-VLDL are a normal feature of the massively hypercholesterolaemic animal model and of the type III hyperlipoproteinaemic patient, they are not a feature of fasting lipids in normal healthy adults, so that the relevance of these findings to the atherogenicity of chylomicron remnants formed as a normal consequence of chylomicron processing is debatable. However in a study of the postprandial response to the ingestion of a high fat meal $(67 \mathrm{~g})$ or a very high fat $(113 \mathrm{~g})$ 
high cholesterol (3 g) meal in man, Bersot et al. (1986) found a lipoprotein fraction containing chylomicron remnants (termed fraction 1) which led to a marked inhibition of $\beta$-VLDL binding to cultured mouse macrophages.

This fraction also led to a massive increase in macrophage triacylglycerols (but not cholesteryl ester) over a $16-\mathrm{h}$ incubation period. However, a fraction taken to represent VLDL remnants (fraction II) did not do so, and led to levels of macrophage triacylglycerols comparable to that obtained with fasting VLDL. In this study, fraction 1 of the postprandial lipoproteins (chylomicron remnants) was found to be rich in apo B-48, apo E and Lp(a). Fraction II (hepatic VLDL remnants) was rich in apo B-100 and apo E but did not contain $\mathrm{Lp}(\mathrm{a})$. This latter lipoprotein has been correlated with clinically evident coronary heart disease (Dahlen et al. 1986). The data of Bersot et al. (1986) show that Lp(a) can be found in postprandial plasma in association with the fraction of triacylglycerol-rich lipoprotein remnants leading to macrophage transformation to foam cells. Whether this is of significance in atherogenesis remains to be seen.

\section{POSTPRANDIAL LIPAEMIA AND CORONARY ARTERY DISEASE}

\section{Triacylglycerol intolerance and coronary artery disease}

Epidemiological studies in man suggest that IDL or remnant lipoproteins are predictors of severity or progression of atherosclerosis (Nordestgaard \& Tybjaerg-Hansen, 1992). An individual's triacylglycerol metabolic capacity, i.e. the extent and duration of lipaemia which occurs after a standardized oral fat load, is a strong determinant of plasma HDL cholesterol, in particular HDL2 cholesterol level. HDL2 cholesterol concentrations are inversely related both to the extent of postprandial lipaemia and to the incidence of coronary artery disease (Patsch et al. 1983).

Evidence suggests that triacylglycerol metabolic capacity determines HDL cholesterol concentration and not vice versa (Patsch et al. 1984, 1987). It appears likely that the strong negative association between HDL cholesterol and coronary artery disease risk represents the residual effect of an incompletely explored triacylglycerol-coronary artery disease association (Miesenböck \& Patsch, 1991).

In a recent clinical study, Bainton et al. (1992) carried out two prospective cohort studies of approximately 5000 middle-aged men, over a 3-5-year follow-up period, to assess the roles of plasma triacylglycerol and $\mathrm{HDL}$ cholesterol concentrations in predicting the occurrence of ischaemic heart disease. Men with triacylglycerol concentrations in the top $20 \%$ of the distribution had a relative odds value for ischaemic heart disease of 2.3 compared with men in the bottom $20 \%$, after adjusting for both plasma total and HDL cholesterol and non-lipid risk factors. Men in the lowest $20 \%$ of the distribution of HDL cholesterol concentration had a relative odds value of 1.7 compared with the top $20 \%$, after adjustment was made for total cholesterol and triacylglycerol concentrations, and non-lipid risk factors. Plasma triacylglycerol concentration predicted major ischaemic events after allowance was made for total and HDL cholesterol concentrations and other risk factors. In the population studied, triacylglycerol was a more important predictor of coronary artery disease than total cholesterol concentration.

The importance of postprandial lipaemia is well demonstrated by recent case control studies evaluating postprandial lipaemia in subjects with angiographically verified presence or absence of coronary artery disease. Groot et al. (1991) studied postprandial triacylglycerol handling in 20 matched pairs of normolipidaemic cases and controls.

Triacylglycerol levels rose to higher postprandial peak concentrations and remained elevated for a longer period of time leading to an overall larger magnitude of postprandial 
lipaemia in the normolipidaemia cases. Large differences in triacylglycerol levels occurred at later times especially after $6 \mathrm{~h}$ postprandially.

Simpson et al. (1990) studied 34 cases (10 with considerable hypercholesterolaemia and 24 normocholesterolaemic), and 18 controls. The magnitude of postprandial lipaemia was higher in the cases, irrespective of whether or not the hypercholesterolaemic subset was included in the analysis; again the postprandial triacylglycerol curves of cases and controls diverged at the later postprandial hours. Unfortunately, no efforts were made in these studies to weigh the risk factor roles of elevated postprandial triacylglycerol with concomitant reduced HDL cholesterol against each other to establish whether postprandial triacylglycerols and HDL cholesterol are each independent predictors of disease.

Patsch et al. (1992) have recently studied the relationship of postprandial triacylglycerol metabolism and coronary artery disease. Sixty-one male subjects with angiographically verified coronary artery disease (cases) and 40 controls were studied. The maximal triacylglycerol increase and the magnitude of an 8 -h postprandial lipaemic phase were higher in cases than in the control subjects. Single postprandial triacylglycerol concentrations $6-8 \mathrm{~h}$ after the test meal were highly discriminatory $(P<0.001)$ in predicting the presence or absence of coronary artery disease. By logistic regression analysis, a diagnostic accuracy of $68 \%$ was achieved in predicting the presence or absence of coronary artery disease.

Thus, the predictive power of triacylglycerol concentration was higher than that of HDL2 cholesterol $(64 \%)$ and equal to that of apolipoprotein $\mathrm{B}$, the most discriminatory parameter in the fasted state. Furthermore, in multivariate analysis, triacylglycerol concentrations were independent predictors of coronary artery disease provided a postprandial challenge test was used. The study strongly suggests that the metabolism of triacylglycerols is a critical determinant of the presence of coronary artery disease. The findings underscore the concept that the negative association between plasma HDL cholesterol concentrations and coronary artery disease is a result of a positive correlation between coronary artery disease and plasma triacylglycerol metabolism, a relationship which can only be clearly demonstrated by a postprandial challenge.

Ryu et al. (1992) studied the relationship between postprandial triacylglycerolaemia and carotid atherosclerosis in middle-aged men. Forty-seven subjects were studied and the extent of alimentary lipaemia was correlated with carotid artery wall thickness as determined by B-mode ultrasonography. Univariate analyses indicated a correlation between peak triacylglycerol response and carotid wall thickness and an inverse relationship to HDL cholesterol. This association between carotid artery wall thickness and the lipaemic response suggests that the atherogenic process is enhanced by prolonged exposure to triacylglycerol-rich chylomicrons.

\section{Triacylglycerol intolerance: effects on other circulating lipoproteins}

O'Meara et al. (1992) studied the interaction between basal plasma triacylglycerol and HDL cholesterol concentrations in determining the magnitude of postprandial triacylglycerolaemia in vivo utilizing the retinyl palmitate loading test to label intestinally derived triacylglycerol-rich particles.

Subjects with low HDL were divided into two groups according to the basal triacylglycerol concentration. Subjects in the high triacylglycerol low HDL group had areas under the triacylglycerol response curve which were very significantly greater $(P<0.0005)$ than those in any other group.

Further evidence for a primary disturbance in triacylglycerol metabolic capacity in a syndrome associated with increased risk of coronary artery disease is demonstrated in the condition of hypo- $\alpha$-lipoproteinaemia where HDL cholesterol and apo A concentrations 
are low and serum apolipoprotein $B$ is elevated in the presence of a normal LDL cholesterol concentration. It often presents with hypertriacylglycerolaemia and is associated with an increased coronary artery disease risk. Postprandial studies by Genest et al. (1986), Bhatnagar et al. (1992) and Ooi et al. (1992) suggested that hypo- $\alpha$-lipoproteinaemia is associated with persistence of triacylglycerol-rich lipoproteins in subjects with and without coronary artery disease. These groups demonstrated that enhanced postprandial lipaemia accounted for the increased coronary artery disease risk in these subjects. Again it is suggested that in this condition the extent of the postprandial fall in HDL cholesterol is related to disturbance in postprandial lipaemia and also to qualitative changes in $\mathrm{LDL}$ particle composition.

The heterogeneity of plasma LDL and the association of a much higher risk of myocardial infarction with a preponderance of the small, dense LDL particles has also been demonstrated by other workers (Tornvall et al. 1991; Campos et al. 1992). Very recent work by Karpe et al. (1993) has shown that the composition of LDL fraction is influenced by postprandial lipid metabolism.

They studied 32 patients with angiographically defined coronary heart disease, 15 of whom had basal hypertriacylglycerolaemia, and 10 controls, after they had received a meal containing $50 \mathrm{~g} / \mathrm{m}^{2}$ of dietary fat. The concentration of plasma LDL cholesterol was similar for the three groups $(4.4,4.0$ and $4.2 \mathrm{mmol} / 1$ respectively), while the $\%$ of LDL as dense LDL $(\mathrm{d}=1.040-1.063 \mathrm{~kg} / \mathrm{l})$ was significantly higher $(56 \%)$ in the hypertriacylglycerolaemic patients compared to controls $(39 \%)$. Following the test meal, the greater the postprandial lipid response, the greater was the concentration of dense LDL particles. This was reflected in a clear positive association $(r=+0 \cdot 50)$ between postheparin lipoprotein lipase activity and light LDL cholesterol $(\mathrm{d}=10 \cdot 19-10 \cdot 04 \mathrm{~kg} / \mathrm{l})$. In effect, the greater the activity of this enzyme, the lower the postprandial response and the greater the proportion of LDL as light LDL. The significance of this work is that the metabolism of triacylglycerol-rich lipoproteins in the postprandial phase is now seen to impinge on LDL metabolism in a way that reveals the complexity of the latter and the central role played by lipoprotein lipase in mediating these disturbances in postprandial lipoproteins.

Complex segregation analyses in normolipidaemic and hyperlipidaemic kindreds suggest that LDL size is controlled by a single major locus designated ATHS (atherosclerosis susceptibility), with dominance of the pattern B LDL allele, but with incomplete penetrance in younger males and premenopausal females. Nishina et al. (1992) mapped the ATHS gene to the short arm of chromosome 19, near or at the LDL receptor locus. Miesenböck et al. (1993) demonstrated abnormalities characteristic of the 'atherogenic lipoprotein phenotype' in two Austrian families affected by a mis-sense mutation of the lipoprotein lipase gene.

There was enhanced postprandial lipaemia and phenotypic similarities between these Austrian families and the pattern B lipoprotein phenotype described by Austin et al. (1990). This study suggests that the metabolic setting underlying the 'atherogenic lipoprotein phenotype' is impaired triacylglycerol tolerance of whatever molecular cause. The existence of a single gene defect causing impaired triacylglycerol tolerance appears to link pronounced lipaemia to LDL pattern $B$, and suggests that the former is a necessary prerequisite for the latter.

\section{CONCLUSIONS}

Postprandial lipaemia provides a daily state of challenge to triacylglycerol transport. A poor ability to cope with the challenge of a postprandial lipid load is likely to increase the risk of cardiovascular disease because it provides ample opportunity for cholesteryl esters 
to be shunted from LDL and HDL into triacylglycerol-rich particles, converting them into potentially atherogenic particles. Shunting of cholesteryl esters into triacylglycerol-rich lipoproteins appears to be inversely related to triacylglycerol metabolic capacity.

In both normal individuals and those with coronary artery disease there is evidence to suggest that disturbance in LPL may underlie impaired triacylglycerol metabolic capacity. Effects of age, sex, exercise and some effects of diet on postprandial lipaemia may also be explained through variation in the activity of lipoprotein lipase.

In relation to reducing risk of coronary artery disease the optimum situation appears to be one in which triacylglycerol accumulation in the postprandial phase can be avoided, or sufficiently limited, so that endogenous cholesteryl ester remains in HDL and LDL. Measures aimed at improving triacylglycerol metabolic capacity - a prudent diet, weight reduction and aerobic exercise-and triacylglycerol-lowering drugs should probably assume more importance in the preventive management of the atherosclerotic process.

\section{REFERENCES}

Albrink, M. J., Fitzgerald, J. R. \& Mann, E. B. (1958). Reduction of alimentary lipaemia by glucose. Metabolism 7, $162-171$.

Aldred, H. E., Lockwood, F. D. \& Hardman, A. E. (1993). Moderate exercise prior to ingestion of a high fat meal decreases postprandial lipaemia. Proceedings of the Nutrition Society' (In the Press).

Austin, M. A., King, M.-C., Vranizan, K. M. \& Krauss, R. M. (1990). Atherogenic lipoprotein phenotype: a proposed genetic marker for coronary heart disease risk. Circulation 82, 495-506.

Bainton, D., Miller, N. E., Bolton, C. H., Yarnell, J. W.. Sweetnam, P. M., Baker, I. A., Lewis, B. \& Elwood, P. C. (1992). Plasma triglyceride and high density lipoprotein cholesterol as predictors of ischaemic heart disease in British men. The Caerphilly and Speedwell Collaborative Heart Disease Studies. British Heart Journal 68, 60-66.

Berr, F. \& Kern, F. (1984). Plasma clearance of chylomicrons labeled with retinyl palmitate in healthy human subjects. Journal of Lipid Research 25, 805-812.

Bersot, T. P., Innerarity, T. L., Pitas, R. E., Rall, S. C., Weisgraber, K. H. \& Mahley, R. W. (1986). Fat feeding in humans induces lipoproteins of density less than 1.006 that are enriched in apolipoprotein [a] and that cause lipid accumulation in macrophages. Journal of Clinical Investigation 77, 622-630.

Bhatnagar, D., Durrington, P. N. \& Arrol, S. (1992). Postprandial plasma lipoprotein responses to a mixed meal in subjects with hyperapobeta-lipoproteinaemia. Clinical Biochemistry 25, 341343.

Brouwer. C. B., de Bruin, T. W. A., Jansen, H. \& Erkelens, D. W. (1993). Different clearance of intravenously administered olive oil and soybean-oil emulsions: role of hepatic lipase. American Journal of Clinical Nutrition 57, 533-539.

Campos, H., Genest, J. J., Blijlevens, E., McNamara, J. R., Jenner, J. L., Ordovas, J. M., Wilson, P. W. F. \& Schaefer, E. J. (1992). Low density lipoprotein particle size and coronary artery disease. Arteriosclerosis and Thrombosis 12, 187-195.

Carey, M. C., Small, D. M. \& Bliss, C. M. (1983). Lipid digestion and absorption. Annual Review of Physiolog. 45, 651-677.

Chen, Q., Florén, C.-H., Nilsson, A. \& Infante, R. (1991). Regulation of chylomicron remnant uptake in the human hepatoma cell-line Hep G2. Role of the low-density lipoprotein receptor. Biochimica et Biophysica Acta 1083, 173-178.

Chen, Y.-D. I., Skowronski, R., Coulston, A. M., Pietarinen, J., Hollenbeck, C. B. \& Reaven, G. M. (1992). Effect of acute variations in dictary fat and carbohydrate intake on retinyl ester content of intestinally derived lipoproteins. Journal of Clinical Endocrinology \& Metabolism 74, 2832.

Choi, S. Y., Fong, L. G., Kirven, M. J. \& Cooper, A. D. (1991). Use of an anti-low density lipoprotein receptor antibody to quantify the role of the LDL receptor in the removal of chylomicron remnants in the mouse in vivo. Journal of Clinical Investigation 88, 1173-1181.

Chung, B. H., Segrest, J. P., Smith, K., Griffin, F. M. \& Brouillette, C. G. (1989). Lipolytic surface remnants of triglyceride-rich lipoproteins are cytotoxic to macrophages but not in the presence of high density lipoprotein. A possible mechanism of atherogenesis? Journal of Clinical Investigation 83, 1363-1374.

Cohen. J. C. (1989). Protein ingestion does not affect postprandial lipaemia or chylomicron-triglyceride clearance. European Journal of Clinical Nutrition 43, 497-499.

Cohen. J. C. \& Berger, G. M. (1990). Effects of glucose ingestion on postprandial lipemia and triglyceride clearance in humans. Journal of Lipid Research 31, 597-602.

Cohen, J. C., Noakes, T. D. \& Benade, A. J. S. (1989). Postprandial lipemia and chylomicron clearance in athletes and in sedentary men. American Journal of Clinical Nutrition 49, 443-447. 
Cohen, J. C.. Noakes, T. D. \& Benade, A. J. S. (1988). Serum triglyceride responses to fatty meals : effects of meal fat content. American Journal of Clinical Nutrition 47, 825827.

Cohen, J. C. \& Schall, R. (1988). Reassessing the effects of simple carbohydrates on the serum triglyceride responses to fat meals. American Journal of Clinical Nutrition 48, 1031-1034.

Cohn, J. S., McNamara, J. R., Cohn, S. D., Ordovas, J. M. \& Schaefer, E. J. (1988). Postprandial plasma lipoprotein changes in human subjects of different ages. Journal of Lipid Research 29, 469-479.

Cohn, J. S., McNamara, J. R., Krasinski, S. D., Russell, R. M. \& Schaefer, E. J. (1989). Role of triglyceride-rich lipoproteins from the liver and intestine in the etiology of postprandial peaks in plasma triglyceride concentration. Metabolism 38, 484-490.

Cryer, A., Riley, S. E., Williams, E. R. \& Robinson, D. S. (1976). Effect of nutritional status on rat adipose tissue, muscle and post-heparin plasma clearing factor lipase activities: their relationship to triglyceride fatty acid uptake by fat-cells and to plasma insulin concentrations. Clinical Science and Molecular Medicine 50, 213-221.

Dahlen, G. H., Guyton, J. R., Attar, M., Farmer, J. A., Kautz, J. A. \& Gotto, A. M. (1986). Association of levels of lipoprotein Lp(a), plasma lipids, and other lipoproteins with coronary artery disease documented by angiography. Circulation 74, 758-765.

Davidson, N. O., Kollmer, M. E. \& Glickman, R. M. (1986). Apolipoprotein synthesis in rat small intestine: regulation by dietary triglyceride and biliary lipid. Journal of Lipid Research 27, 30-39.

Davidson, N. O., Magun, A. M., Brasitus, T. A. \& Glickman, R. M. (1987). Intestinal apolipoprotein A-I and B48 metabolism: effects of sustained alterations in dietary triglyceride and mucosal cholesterol flux. Journal of Lipid Research 28, 388-402.

Demacker, P. N. M., Reijnen, I. G. M., Katan, M. B., Stuyt, P. M. J. \& Stalenhoef, A. F. H. (1991). Increased removal of remnants of triglyceride-rich lipoproteins on a diet rich in polyunsaturated fatty acids. European Journal of Clinical Investigation 21, 197-203.

Durrington, P. N. (1989). Hyperlipidaemia: Diagnosis and Management. London: Butterworth.

Eckel, R. H. (1989). Lipoprotein lipase, a multifactorial enzyme relevant to common metabolic diseases. New England Journal of Medicine 320, 1060-1068.

Genest, J., Sniderman, A., Cianflone, K., Teng, B., Wacholder, S., Marcel, Y. \& Kiviterovich, P. (1986). Hyperapobetalipoproteinemia. Plasma lipoprotein responses to oral fat load. Arteriosclerosis 6, 297304.

Goldstein, J. L., Ho, Y. K., Brown, M. S., Innerarity, T. L. \& Mahley, R. W. (1980). Cholesteryl ester accumulation in macrophages resulting from receptor-mediated uptake and degradation of hypercholesterolemic canine $\beta$-very low density lipoproteins. Journal of Biological Chemistry 255, 1839-1848.

Griglio, S., Sultan, F. \& Lagrange, D. (1992). Role of hepatic lipase in the catabolism of chylomicron remnants in the rat. Diabète et Métabolisme 18, 150-155.

Groot, P. H. E., van Stiphout, W. A. H. J., Krauss, X. H., Jensen, H., van Tol, A., van Ramshorst, E., Chin-On, S., Hofman, A., Cresswell, S. R. \& Hanekes, L. (1991). Postprandial lipoprotein metabolism in normolipidemic men with and without coronary artery disease. Arteriosclerosis and Thrombosis 11, 653-662.

Grundy, S. M. \& Mok, H. Y. I. (1976). Chylomicron clearance in normal and hyperlipidemic man. Metabolism 25, 1225-1239.

Harris, W. S., Connor, W. E., Alam, N. \& Illingworth, D. R. (1988). Reduction of postprandial triglyceridemia in humans by dietary n-3 fatty acids. Journal of Lipid Research 29, 1451-1460.

Heimberg. M., Dunn, G. D. \& Wilcox, H. G. (1974). The derivation of plasma-free fatty acids from dietary neutral fat in man. Journal of Laboratory and Clinical Medicine 83, 393-402

Herz, J., Hamann, U., Rogne, S., Myklebost, O., Gausepohl, H. \& Stanley, K. K. (1988). Surface location and high affinity for calcium of a $500-\mathrm{kd}$ liver membrane protein closely related to the LDL-receptor suggest a physiological role as lipoprotein receptor. EMBO Journal 7, 4119-4127.

Huff, M. W., Evans, A. J., Sawyez, C. G., Wolfe, B. M. \& Nestel, P. J. (1991). Cholesterol accumulation in J774 macrophages induced by triglyceride-rich lipoproteins. Comparison of very low density lipoprotein from subjects with type III, IV and V hyperlipoproteinemias. Arteriosclerosis and Thrombosis 11, 221-233.

Imaizumi, K., Havel, R. J., Fainaru, M. \& Vigne, J. L. (1978). Origin and transport of the A-I and arginine-rich apolipoproteins in mesenteric lymph of rats. Journal of Lipid Research 19. 10381046.

Johnston, J. M. (1968). Mechanism of fat absorption. In Handbook of Physiology, Section 6, Alimentary. Canal, Vol. III, pp. 1353-1375. Washington. D.C.: American Physiological Society.

Karpe, F., Tornvall, P., Olivecrona. T. Steiner, G., Carlson, L. A. \& Hamsten, A. (1993). Composition of human low density lipoprotein: effects of postprandial triglyceride-rich lipoproteins, lipoprotein lipase, hepatic lipase and cholesteryl ester transfer protein. Atherosclerosis $98,3349$.

Kashyap. M. L., Barnhart, R. L., Srivastava, L. S., Perisutti, G., Allen, C., Hogg, E., Glueck, C. J. \& Jackson, R. L. (1983). Alimentary lipemia: plasma high-density lipoproteins and apoliproteins CII and CIII in healthy subjects. American Journal of Clinical Nutrition 37, 233-243.

Kay, R. M., Rao, S., Arnott, C., Miller, N. E. \& Lewis, B. (1980). Acute effects of the pattern of fat ingestion on plasma high-density lipoprotein components in man. Atherosclerosis 36, 567-573.

Kinnunen, P. K. J. \& Ehnholm, C. (1976). Effect of serum and C-apoproteins from very low density lipoproteins on human postheparin plasma hepatic lipase. FEBS Letters 65, 354357.

Krasinski, S. D., Cohn, J. S., Russell, R. M. \& Schaefer, E. J. (1990). Postprandial plasma vitamin A metabolism in humans: a reassessment of the use of plasma retinyl esters as markers for intestinally derived chylomicrons and their remnants. Metabolism 39, 357365 . 
Lefevre, M., Chuang, M.-Y. \& Roheim, P. S. (1986). ApoA-IV metabolism in the rat: role of lipoprotein lipase and apolipoprotein transfer. Journal of Lipid Research 27, 1163-1173.

Levy, E., Roy, C. C., Goldstein, R., Bar-On, H. \& Ziv, E. (1991). Metabolic fate of chylomicrons obtained from rats maintained on diets varying in fatty acid composition. Journal of the American College of Nutrition 10 , 69- 78.

Lovegrove, J. A. L., Morgan, L. M., Isherwood, G. \& Williams, C. M. (1993). Effect of addition of guar gum to an acute test meal on postprandial lipaemia in normal healthy adults. Proceedings of the Nutrition Society. (In the Press).

Mahley, R. W. (1982). Atherogenic hyperlipoproteinemia. The cellular and molecular biology of plasma lipoproteins altered by dietary fat and cholesterol. Medical Clinics of North America 66, 375402.

Mann, C. J., Yen, F. T., Grant. A. M. \& Bihain, B. E. (1991). Mechanism of plasma cholesteryl ester transfer in hypertriglyceridemia. Journal of Clinical Investigation 88, 2059-2066.

Mann,. J. I., Truswell, A. S. \& Pimstone, B. L. (1971). The different effects of oral sucrose and glucose on alimentary lipaemia. Clinical Science 41, $123-129$.

Mansbach, C. M. \& Parthasarathy, S. (1982). A re-examination of the fat of glyceride-glycerol in neutral lipid absorption and transport. Journal of Lipid Research 23, 1009-1019.

Miesenböck, G., Hölzl, B., Föger, B., Brandstätter, E., Paulweber, B., Sandhofer, F. \& Patsch, J. R. (1993). Heterozygous lipoprotein lipase deficiency due to a missense mutation as the cause of impaired triglyceride tolerance with multiple lipoprotein abnormalities. Journal of Clinical Investigation 91, 448-455.

Miesenböck, G. \& Patsch. J. R. (1991). Coronary artery disease: synergy of triglyceride-rich lipoproteins and HDL. Cardiovascular Risk Factors 1, 293-299.

Murphy, M. C., Zampelas, A., Puddicombe, S. M., Furlonger, N. P., Morgan, L. M. \& Williams, C. M. (1993). Pre-translational regulation of the expression of the lipoprotein lipase gene by dietary fatty acids in the rat. British Journal of Nutrition (In the Press).

Nestel. P. J. (1964). Relationship between plasma triglycerides and removal of chylomicrons. Journal of Clinical Investigation 43, 943-949.

Nestel, P. J., Connor, W. E., Reardon, M. F., Connor, S., Wong, S. \& Boston, R. (1984). Suppression by diets rich in fish oil of very low density lipoprotein production in man. Journal of Clinical Investigation 74, 8289.

Nishina, P. M., Johnson. J. P., Naggert, J. K. \& Krauss, R. M. (1992). Linkage of atherogenic lipoprotein phenotype to the low density lipoprotein receptor locus on the short arm of chromosome 19. Proceedings of the National Academy of Sciences of the USA 89,708 712

Nordestgaard, B. G. \& Tybjaerg-Hansen, A. (1992). IDL, VLDL, chylomicrons and atherosclerosis. European Journal of Epidemiology 8 (Suppl. 1), 9298.

Ockner, R. K. \& Manning. J. A. (1974). Fatty acid-binding protein in small intestine. 4. Identification, isolation, and evidence for its role in cellular fatty acid transport. Journal of Clinical Investigation 54, 326338.

O'Doherty, P. J. A. \& Kuksis, A. (1974). Microsomal synthesis of di- and triacylglycerols in rat liver and Ehrlich ascites cells. Canadian Journal of Biochemistry 52, 514-524.

Olefsky, J. M., Crapo, P. \& Reaven. G. M. (1976). Postprandial plasma triglyceride and cholesterol responses to a low-fat meal. American Journal of Clinical Nutrition 29, 535-539.

O’Meara, N. M., Lewis, G. F., Cabana, V. G. \& Iverius, P. H. (1992). Role of basal triglyceride and high density lipoprotein in determination of postprandial lipid and lipoprotein responses. Journal of Clinical Endocrinolog. and Metabolism 75, 465-471.

Ooi, T. C., Simo, I. E. \& Yakichuk, J. A. (1992). Delayed clearance of postprandial chylomicrons and their remnants in the hypoalphalipoproteinemia and the mild hypertriglyceridemia syndrome. Arteriosclerosis and Thrombosis 12, 1184-1190.

Parks, J. S., Johnson, F. L., Wilson, M. D. \& Rudel, L. L. (1990). Effect of fish oil diet on hepatic lipid metabolism in nonhuman primates: lowering of secretion of hepatic triglyceride but not apoB. Journal of Lipid Research 31, 455-466.

Patsch, J. R., Karlin, J. B., Scott, L. W., Smith, L. C. \& Gotto, A. M. (1983). Inverse relationship between blood levels of high density lipoprotein subfraction 2 and magnitude of postprandial lipemia. Proceedings of the National Academy of Sciences of the USA 80, 1449-1453.

Patsch, J. R., Miesenböck, G., Hopferwieser, T., Muhlberger, V.. Knapp, E., Dunn, J. K.. Gotto, A. M. \& Patsch, W. (1992). Relation of triglyceride metabolism and coronary artery disease. Studies in the postprandial state. Arteriosclerosis and Thrombosis 12, 13361345.

Patsch. J. R., Prasad, S., Gotto, A. M. \& Bengtsson-Olivecrona, G. (1984). Postprandial lipemia. A key for the conversion of high density lipoprotein.2 into high density lipoprotein ${ }_{3}$ by hepatic lipase. Journal of Clinical Investigation 74, 2017-2023.

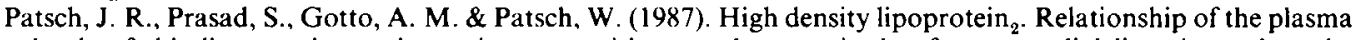
levels of this lipoprotein species to its composition, to the magnitude of postprandial lipemia. and to the activitics of lipoprotein lipase and hepatic lipase. Journal of Clinical Investigation 80, 341-347.

Peel, A. S., Zampelas, A., Williams, C. M., Howland, R. J., Gould, B. J., Chakraborty, J. C. \& Ah-Sing, E. (1993). Specific measurement of apolipoprotein B-48 with a novel specific antibody: discrepancies with retinyl palmitate analysis. International Symposium on 'The Lipid Triad (Triglyceride, HDL, LDL) and Cardiovascular Diseases', Milan. 
Pfeffer, P. E., Sampugna, J., Schwartz, D. P. \& Shoolery, J. N. (1977). Analytical ${ }^{13}$ C NMR: detection, quantitation, and positional analysis of butyrate in butter oil. Lipids 12, 869-871.

Redard, C. L., Davis, P. A. \& Schneeman, B. O. (1990). Dietary fiber and gender: effect on postprandial lipemia. American Journal of Clinical Nutrition 52, 837-845.

Reichl, D. \& Miller, N. E. (1986). The anatomy and physiology of reverse cholesterol transport. Clinical Science 70, 221-231.

Ryu, J. E., Howard, G., Craven, T. E., Bond, M. G., Hagaman, A. P. \& Crouse, J. R. (1992). Postprandial triglyceridemia and carotid atherosclerosis in middle-aged subjects. Stroke 23, 823-828.

Sherill, B. C., Innerarity, T. L. \& Mahley, R. W. (1980). Rapid hepatic clearance of the canine lipoproteins containing only the $\mathrm{E}$ apoprotein by a high affinity receptor. Identity with the chylomicron remnant transport process. Journal of Biological Chemistry 255. 18041807.

Shiau, Y. F., Boyle, J. T., Umstetter, C. \& Koldovsky, O. (1980). Apical distribution of fatty acid esterification capacity along the villus-crypt unit of rat jejunum. Gastroenterology 79, 47-53.

Simpson, H. S., Williamson, C. M., Olivecrona, T., Pringle, S., Maclean, J., Lorimer, A. R., Bonnefons, F., Bogaievsky, Y., Packard, C. J. \& Shepherd, J. (1990). Postprandial lipemia, fenofibrate and coronary artery disease. Atherosclerosis 85, 193-202.

Spooner, P. M., Chernick, S. S., Garrison, M. M. \& Scow, R. O. (1979). Development of lipoprotein lipase activity and accumulation of triacylglycerol in differentiating 3T3-Ll adipocytes. Effects of prostaglandin $F_{2 x}$ 1-methyl-3-isobutylxanthine, prolactin, and insulin. Journal of Biological Chemistry 254. 13051311.

Tornvall, P., Karpe, F., Carlson, L. A. \& Hamsten, A. (1991). Relationships of low density lipoprotein subfractions to angiographically defined coronary artery disease in young survivors of myocardial infarction. Atherosclerosis $\mathbf{9 0}, 67-80$.

Van Berkel, T. J. C., Kruijt, J. K., Scheek, L. M. \& Groot, P. H. E. (1983). Effect of apolipoproteins E and C-III on the interaction of chylomicrons with parenchymal and non-parenchymal cells from rat liver. Biochemical Journal 216, 7180

Van Lenten, B. J., Fogelman, A. M., Jackson, R. L., Shapiro, S., Haberland, M. E. \& Edwards, P. A. (1985). Receptor-mediated uptake of remnant lipoproteins by cholesterol-loaded human monocyte-macrophages. Journal of Biological Chemistry 260. 8783-8788.

Weintraub, M. S., Eisenberg. S. \& Breslow, J. L. (1987a). Dictary fat clearance in normal subjects is regulated by genetic variation in apolipoprotein E. Journal of Clinical Investigation 80, 1571-1577.

Weintraub, M.S., Eisenberg. S. \& Breslow. J. L. (1987b). Different patterns of postprandial lipoprotein metabolism in normal, type IIa, type III and type IV hyperlipoproteinemic individuals. Effects of treatment with cholestyramine and gemfibrozil. Journal of Clinical Investigation 79, 1110-1119.

Weintraub, M. S., Rosen, Y., Otto, R., Eisenberg, S. \& Breslow, J. L. (1988a). Physical exercise conditioning in the absence of weight loss reduces fasting and post-prandial triglyceride-rich lipoprotein levels. Circulation 79. 1007-1014.

Weintraub, M. S., Zechner, R., Brown, A., Eisenberg, S. \& Breslow, J. L. (1988 $b$ ). Dietary polyunsaturated fats of the $\omega-6$ and $\omega-3$ series reduce postprandial lipoprotein levels. Chronic and acute effects of fat saturation on postprandial lipoprotein metabolism. Journal of Clinical Investigation 82, 18841893.

Wellc. S. (1984). Metabolic responses to a meal during rest and low-intensity exercise. American Journal of Clinical Nutrition 40, 990-994.

Williams, C. M., Moore, F., Morgan, L. M. \& Wright, J. (1992). Effects of n-3 fatty acids on postprandial triglyceride and hormone concentrations in normal subjects. British Journal of Nutrition 69, 6378.

Zampelas, A., Ah-Sing, E., Chakraboraty, J., Murphy, M., Peel. A., Wright. J. \& Williams, C. M. (1993a). The use of retinyl palmitate to measure clearance of chylomicrons and chylomicron remnants following meals of different fatty acid compositions. Biochemical Society Transactions 21, $137 \mathrm{~S}$.

Zampelas, A., Williams, C. M., Morgan, L. M., Wright, J. \& Quinlan, P. T. (1993b). The effect of triacylglycerol fatty acid positional distribution on postprandial plasma metabolite and hormone responses in normal adult men. British Journal of Nutrition (In the Press).

Zilversmit, D. B. (1979). Atherogenesis: a postprandial phenomenon. Circulation 60, 473-485.

Zilversmit, D. B. \& Hughes, L. B. (1973). Incorporation in vivo of labeled plasma cholesterol into aortas of young and old rabbits. Atherosclerosis 18, 141-152. 